\title{
Preparation and Characteristics of Arginine Oleate Liquid Crystal Holding a Large Amount of Water
}

\author{
Teruhisa KaneKo $^{1}{ }^{*}$, Yurie YAmaokA ${ }^{1}$, Chihiro KAISE ${ }^{1}$, Masanori ORITA ${ }^{3}$, \\ Hideki $\mathrm{SAKAI}^{2,3}$ and Masahiko ABE ${ }^{2,3}$ \\ ${ }^{1} R / D$ Control Department, SHU UEMURA INC. \\ (Setagaya, Tokyo 156-0054, JAPAN) \\ ${ }^{2}$ Faculty of Science and Technology, Tokyo University of Science \\ (Noda, Chiba 278-8510, JAPAN) \\ ${ }^{3}$ Institute of Colloid and Interfacial Science, Tokyo University of Science \\ (Shinjuku, Tokyo 162-8601, JAPAN)
}

Edited by H. Kunieda, Yokohama Nat. Univ., and accepted January 31, 2005 (received for review December 9, 2004)

\begin{abstract}
Solution properties of arginine oleate (ArgOA) were investigated by means of small angle X-ray scattering device, tensiometer, transmittance measuring device, transmission electron microscope, NMR, etc. Whereas arginine stearate which is different in hydrophobic moiety or sodium oleate which is different in counterion from ArgOA formed lamellar liquid crystals in a limited region, ArgOA formed over a wide ranges of temperature and concentration. The surface tension versus concentration curve of ArgOA had two bending points ( $\mathrm{C} 1$ and $\mathrm{C} 2$ ). When the state of its aqueous solution was observed, transmittance of the aqueous solution decreased in the concentration range of $\mathrm{C} 1$ and more and, in the region until $\mathrm{C} 2$ where the concentration further increased, particles of several tens $\mathrm{nm}$ and several hundreds $\mathrm{nm}$ were observed. At concentrations above $\mathrm{C} 2$, the viscosity of the aqueous solution began to increase due to the formation of bigger molecular aggregates. The formation of micelles, vesicle-like highly associated aggregates, and lamellar liquid crystals with large amount of water were observed as a result of an increase in concentration of ArgOA.

Key words: arginine oleate, lamellar liquid crystal, surface tension, viscosity, micelle, vesicle, transmittance, NMR
\end{abstract}

\section{Introduction}

Unsaturated fatty acids play an important role in vivo not only as energy sources but also as main components of biomembranes (1-3). It is well known that fluidity of biomembrane is affected by its characteristic dynamic structure and is dependent on the unsaturated fatty acid, oleic acid (4-8). Oleic acid, which has a double bond at C9 position in its molecule and freely-rotating, adjacent methylene groups, is one of the representative cismonoene unsaturated fatty acids which are able to bend comparatively freely. Until recently the purity of avail- able oleic acid is low, and there has been restriction in its study for basic physical properties as well as its application for a speciality chemical field such as pharmaceuticals, cosmetics and biosciences. In recent years however, a product where purity is $99 \%$ or greater is constantly available and there have been many reports on the analysis of its basic physical properties (9-13) as well as the basic physical properties of nonionic surfactants which are its derivatives (14-16) and its use as an enhancer of drug penetration through the skin (17-20). These studies have shown that oleic acid has a big space-filling volume $(21,22)$ based on cis-type double

\footnotetext{
*Correspondence to: Teruhisa KANEKo, R/D Control Department, SHU UEMURA INC., 4-23-5 Sakuragaoka, Setagaya-ku, Tokyo 156-0054,
} JAPAN 
bond of its hydrophobic moiety and a fluidity near body temperature of constant-temperature animals. Incidentally, the melting point of oleic acid is $13.4^{\circ} \mathrm{C}$ for an $\alpha$ type and is $16.3^{\circ} \mathrm{C}$ for a $\beta$-type, on the other hand, in the case of stearic acid having the same hydrocarbon chain length as oleic acid, it is $69.6^{\circ} \mathrm{C}(12)$.

L-Arginine is one of basic essential amino acids in living body and shows four ion dissociation states depending upon $\mathrm{pH}$ of its aqueous solution (Fig. 1) $(23,24)$. For example, since the guanidyl group at $\omega$ position shows a strong basic property, it neutralizes substances having counterion, whereas the carboxyl group and amino group at $\alpha$-position have a characteristic of forming self dipolar zwitterions. It has been reported that many amino acids have melting points of $200^{\circ} \mathrm{C}$ or higher, because they form the zwitterion that has an ionic crystalline structure similar to inorganic salts (23). Amino acids have been very useful in the field of cosmetics as well and play an important role for governing a moisturizing ability of the skin being called a NMF (natural moisturizing factor) (25).

Combining the properties of big space-filling volume and fluidity of oleic acid with the high self dipolar zwitterion forming ability of L-arginine should give rise to a novel function, namely the formation of a biomimetic film.

In view of the above, in the present study, characteristic solution properties of an amphiphilic substance (arginine oleate) comprising highly purified (99.9\%) oleic acid and L-arginine were investigated utilizing various surface chemical means.

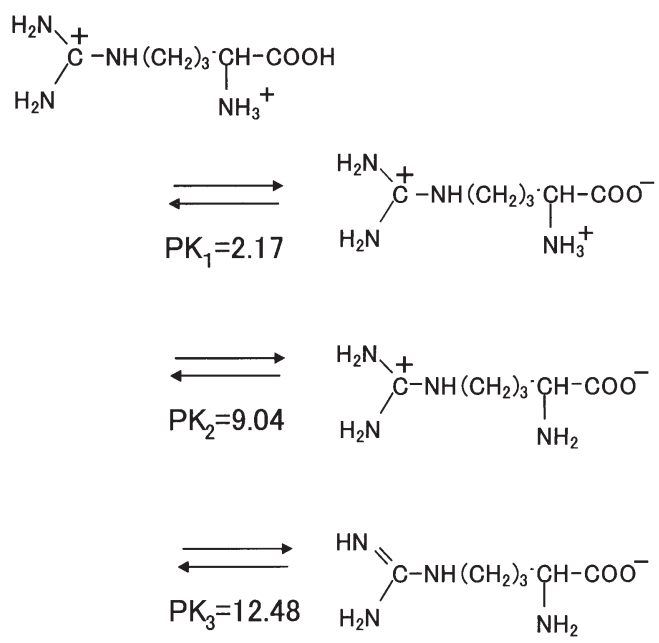

Fig. 1 Four Different Dissociate Ion States of L-arginine Depending on $\mathrm{pH}$.

\section{Experimental}

\subsection{Materials}

Arginine oleate (ArgOA) is a fatty acid soap where hydrophobic moiety is oleic acid (OA) and counterion is L-arginine (Arg). Oleic acid of $99.9 \%$ purity (Extra Oleic 99 manufactured by NOF Corporation) and Larginine (of a pharmaceutical grade manufactured by Kyowa Hakko Kogyo) were used for the preparation. Preparation method was that L-arginine was added to distilled water of $75^{\circ} \mathrm{C}$ and dissolved with stirring, oleic acid was then gradually dropped to the solution and the mixture was subjected to natural cooling. Their adding amounts were in a molar ratio of $\mathrm{Arg} / \mathrm{OA}=1 / 1$. After that, annealing was conducted (by three cycles where one cycle comprised allowing to stand at $-5^{\circ} \mathrm{C}$ for 12 hours and at room temperature for 12 hours, followed by stirring) to prepare a homogeneous solution. The resulting $10 \mathrm{wt} \%$ aqueous solution of arginine oleate was freeze-dried to give powder of arginine oleate (ArgOA) crystals. It was confirmed by a Karl Fisher's method that amount of water in this ArgOA was 2 to 3\%. Distilled water for injection (Otsuka Pharmaceutical) was used as the distilled water. Preparation of sodium oleate $(\mathrm{NaOA}$; molar ratio $=1 / 1)$ and of arginine stearate $(\operatorname{ArgSA}$; molar ratio $=1 / 1)$ was also carried out by the same method.

\subsection{Preparation of Phase Diagram}

Preparation of a phase diagram was conducted in such a manner that a sample having a predetermined composition was placed in a screwed test tube equipped with a Teflon seal and allowed to stand in a constanttemperature water bath and the resulting state was observed. For the measurement of phase transition temperature, a differential scanning calorimeter (DSC 6100 manufactured by Seiko Instruments) was used. Observation of the liquid crystalline structure was conducted in such a manner that a temperature rising stage (type THMS 600 manufactured by Linkam) was installed in an inverted optical microscope (type IMT-2 manufactured by Olympus) and changes in temperature were observed under a transmission Nomarski type differential interference contrast or under polarized light. Final confirmation of liquid crystalline structure was carried out by a small angle X-ray scattering (SAXS). 


\subsection{Measurement of Small Angle X-ray Scattering (SAXS)}

Final confirmation of liquid crystalline structure and measurement of the interlayer spacing were conducted by means of small angle X-ray scattering (SAXS). As to a device, RU-200 manufactured by Rigaku was used and a sample was filled in stainless steel plates with a thickness of $1 \mathrm{~mm}$ having pores $(5 \mathrm{~mm} \times 40 \mathrm{~mm})$, both surfaces were held by a polyimide film and measurement was conducted at a constant temperature of $25^{\circ} \mathrm{C}$. However, for the measurement by SAXS of a sample in a region where concentration of water was $80 \%$ or more, $\mathrm{ArgOA}$ was diluted in such a manner that data with a good precision were not available by the SAXS used at this time and, therefore, a polarized microscope or a transmission electron microscope (TEM) was used for the observation of a diluted region.

\subsection{Measurement of Surface Tension}

Measurement of surface tension was conducted at $25^{\circ} \mathrm{C}$ by a Wilhelmy method using an automatic tensiometer of a Whilhelmy plate type (type CBVP-Z manufactured by Kyowa Kaimen Kagaku).

\subsection{Measurement of Transmittance}

Measurement of transmittance of a solution upon temperature was conducted at the wavelength of 700 $\mathrm{nm}$ using a UV/VIS Spectrophotometer (V-550 manufactured by Jasco).

\subsection{TEM Observation by a Freeze Frac- ture Method}

Preparation of a sample for observation of an aqueous solution of ArgOA under a transmission electron microscope (TEM) was carried out by a freeze fracture method. Thus, a frozen replica of the sample was prepared by a frozen replica manufacturing device (FR7000A manufactured by Hitachi Science Systems) with using a quick freezing system (EM CPC manufactured by Leica). A method for replica preparation was that the sample solution was quickly frozen in liquid propane $\left(-187^{\circ} \mathrm{C}\right)$ and platinum carbon was vapordeposited on the cracked cross section to form shadows. After that, the above was washed with acetone and distilled water and transferred to a grid of 150 mesh made of copper to prepare a replica. The prepared metal replica membrane was observed under a TEM (JEM1200EX manufactured by Nippon Denshi).

\subsection{Measurement of Viscoelasticity}

Measurement of viscoelasticity was conducted using a rheometer of a stress control type (Carri-Med CLS 2100 manufactured by TA-Instruments). Viscosity was calculated by an approximation of a curve for shearing stress versus shearing velocity by a Bingham's formula. Temperature of the sample was controlled at $25 \pm$ $0.1^{\circ} \mathrm{C}$ by a Peltier element.

\section{$2 \cdot 8$ Measurement of $\mathbf{p H}$}

Measurement of $\mathrm{pH}$ was conducted using $\mathrm{pH}$ electrodes (GST-5311C manufactured by TOA Electric) and ion meter (1M-40S manufactured by TOA Electric).

\section{$2 \cdot 9$ Measurement of NMR}

Measurement of chemical shifts for amino group proton based on ${ }^{1} \mathrm{H}-\mathrm{NMR}$ was conducted by JNM AL-300 Type manufactured by JEOL.

\section{Results and Discussion}

\section{1 Phase Diagram of Arginine Oleate/ Water System}

Figure 2 shows a phase diagram of ArgOA/water system, in which molar ratio of L-arginine to oleic acid is $1 / 1$. As will be apparent from the region (A) of this diagram, a hydrated crystal of ArgOA was present in a very high concentration range of ArgOA, while transition temperature $(\mathrm{Tc})$ to a lamellar liquid crystalline phase suddenly lowered as water increased and, when it

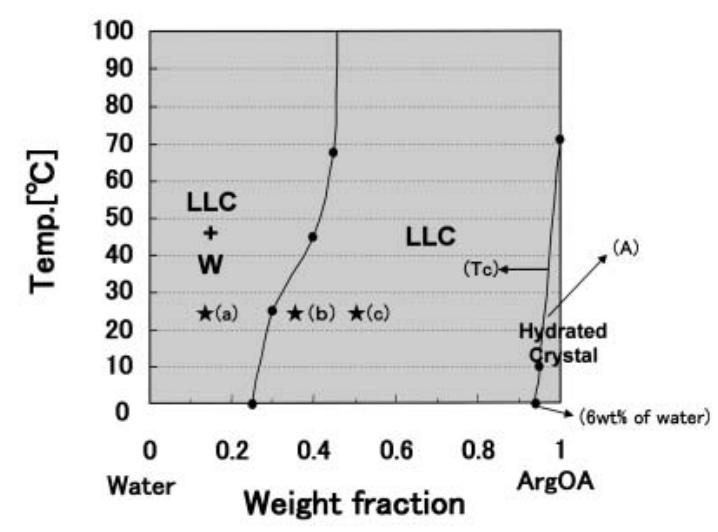

Fig. 2 Phase Diagram of ArgOA-water System.

$\operatorname{ArgOA}(1 / 1$, molar ratio).

LLC : Lamellar Liquid Crystal

$\mathrm{W}$ : Aqueous solution

Tc: Phase transition temperature (LLC-Hydrated Crystal) 


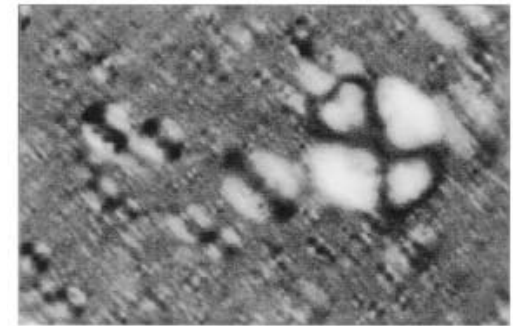

(a)

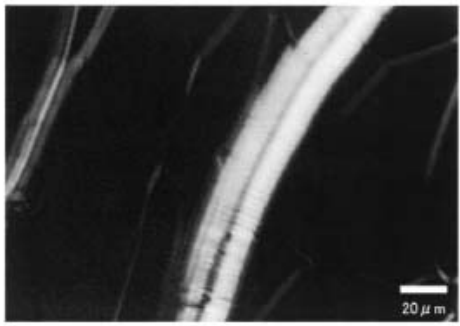

(b)

Fig. 3 Polarized Microscopic Observation.

(a) $15 \mathrm{wt} \% \mathrm{ArgOA}$ aq.solu.

(b) $35 \mathrm{wt} \% \mathrm{ArgOA}$ aq.solu.

exceeded $6 \mathrm{wt} \%$, the temperature became $0^{\circ} \mathrm{C}$ or lower and most of the region was occupied by lamellar liquid crystals. That is because L-arginine as a counterion was apt to be hydrated, and similar phenomena have been observed in potassium stearate, dipalmitoylphosphatidylcholine, etc. (26).

Figure 3 shows pictures under a polarized microscope of aqueous solutions of (a) $15 \mathrm{wt} \%$ of ArgOA and (b) 35 wt $\%$ of $\mathrm{ArgOA}$ in Fig. 2 at $25^{\circ} \mathrm{C}$. In a 15 $\mathrm{wt} \%$ aqueous solution of $\mathrm{ArgOA}$ in the LLC $+\mathrm{W}$ region (a) in the figure, concentric lamellar liquid crystals (multi-lamellar vesicles) dispersed in water were observed, while in a $35 \mathrm{wt} \%$ aqueous solution of ArgOA in the LLC region (b), lamellar liquid crystalline structure was formed.

In addition, as will be noted from the area of the lamellar liquid crystalline region (Fig. 2), it is expected that the lamellar liquid crystal by ArgOA is able to retain a large amount of water in its structural body. Therefore, in order to analyze the structure in more

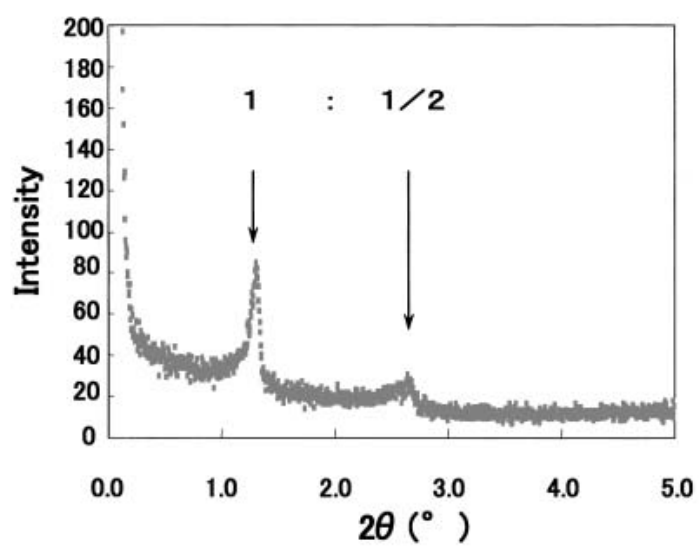

Fig. 4 Small Angle X-ray Diffraction Pattern $\left(25^{\circ} \mathrm{C}\right)$ : ArgOA/Water (1/1 by Weight). detail, a small angle X-ray diffraction pattern $\left(25^{\circ} \mathrm{C}\right)$, where the ratio by weight of $\mathrm{ArgOA} /$ water is $1 / 1$ corresponding to Fig. 2(c), is shown in Fig. 4. The scattering peak ratio of the primary peak to the secondary peak in the small angle diffraction was $1: 1 / 2$, by which the formation of lamellar liquid crystalline structure was confirmed. Then, the interlayer spacing of lamellar liquid crystals by small angle X-ray diffraction was measured (Fig. 5). Incidentally, the ordinate is the interlayer spacing (d) of the lamellar liquid crystals and the abscissa is the ratio $(\mathrm{Cw} / \mathrm{Cao})$ of weight fraction of water $(\mathrm{Cw})$ to that of ArgOA (Cao). Here, spacing (d) of the lamellar liquid crystal was calculated by a Bragg's formula $(2 \mathrm{~d}$ $\sin \theta=\mathrm{n} \lambda$ in which $\mathrm{d}$ is interlayer spacing, $\theta$ is $\mathrm{X}$-ray scattering angle, $\mathrm{n}$ is integer and $\lambda$ is wavelength of incoming $X$-ray) from the scattering peak of small angle X-ray diffraction. It will be considered that an increase in $\mathrm{d}$ means that water molecules are distributed into the hydrophilic parts of the lamellar liquid crystalline structure (27). As will be apparent from Fig. 5, when $\mathrm{Cw} / \mathrm{Cao}$ passed over 0.3 , $\mathrm{d}$ increased almost linearly and became near a constant value when the ratio

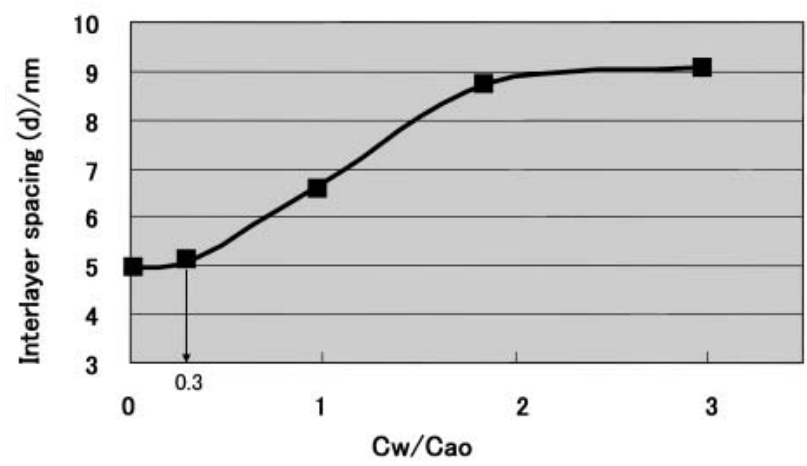

Fig. 5 Interlayer Spacing of LLC Phase as a Function of the Water : ArgOA Weight Ratio $(\mathrm{Cw} / \mathrm{Cao})$ at $25^{\circ} \mathrm{C}$. 
became more than about 2 . This means that more water than the above is unable to be incorporated into the structure but is separated as a water phase being coexisted with the lamellar liquid crystalline phase (LLC + W). Thus, it shows that ArgOA forms lamellar liquid crystals containing about $70 \%$ of water and, at the same time, ArgOA has an ability of retaining more amount of water than lecithin which is a main component of biomembrane (28). Therefore, a multi-lamellar vesicle region of ArgOA shown by LLC $+\mathrm{W}$ of Fig. 2 also retains about $70 \%$ of water in vesicles and a difference in specific gravity from water as the external phase also becomes small, whereby it was relatively stable causing no separation even after one month at room temperature. It has been found that, although ArgOA is a single-chained amphiphilic substance, it has a high ability to form lamellar liquid crystals like branched-chain type (29) or double-chained (30) amphiphilic substances and that much more water is able to be retained in its structural body.

Accordingly, in order to further understand the characteristics of solution properties of ArgOA, investigations were conducted for a phase diagram of sodium oleate/water system using sodium instead of arginine as a counterion and also for arginine stearate/water system using stearic acid instead of oleic acid as a hydrophobic moiety.

\section{$3 \cdot 2$ Phase Diagrams of a Sodium Oleate/ Water System and an Arginine Stearate/Water System}

Figure 6 shows a phase diagram of sodium oleate $(\mathrm{NaOA}) /$ water system. When it is compared with a hydrated crystal region (A) of Fig. 2, the hydrated crystal existed until about $32^{\circ} \mathrm{C}$ even when hydrated to an extent of $60 \%$ as shown in the point (e). It is presumed to be due to the fact that, since counterion for $\mathrm{NaOA}$ is sodium, there is no high hydrating ability of arginine, and changes in Tc as a result of an increase in water concentration do not take place quickly. In an $\mathrm{NaOA} /$ water system, both types of lamellar and hexagonal liquid crystals were present unlike the case of ArgOA. This is considered to be caused by a molecular structure (cone type) originated in the molecular balance between hydrophobic moiety (oleyl group) and hydrophilic moiety (sodium). Furthermore, compared the phase diagram of $\mathrm{NaOA} /$ water system in Fig. $\mathbf{6}$ with that of ArgOA/water system in Fig. 2, NaOA showed a wide range of micellar phase (Wm), while in the case of $\mathrm{ArgOA}$, it showed a wide range of dispersed phase of lamellar liquid crystal (LLC $+\mathrm{W})$. It is interpreted that, since a lateral intermolecular repulsion in $\mathrm{NaOA}$ aggregate is higher than that in ArgOA aggregate with self dipolar zwitterionic interaction, $\mathrm{NaOA}$ forms smaller aggregate (in Wm phase) than the aggregate of ArgOA in LLC $+\mathrm{W}$ phase. As a result of it, it causes more hydrophilicity of $\mathrm{NaOA}$ than hydrophile-lipophile

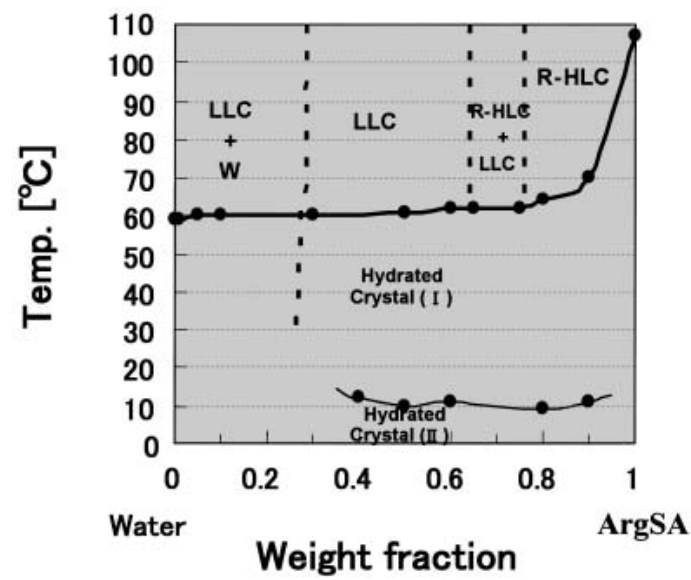

Fig. 7 Phase Diagram of ArgSA-water System.

$\operatorname{ArgSA}(1 / 1$, molar ratio)

LLC : Lamellar Liquid Crystal

R-HLC : Reversed Hexagonal phase

$\mathrm{W}:$ Aqueous solution 
balance(HLB) of ArgOA.

Figur 7 shows a phase diagram of an arginine stearate (ArgSA)/water system where hydrophobic moiety of ArgOA was different. As will be clear from Fig. 7, hydrated crystal of ArgSA was present in a wide concentration range at about $60^{\circ} \mathrm{C}$ and lower. This is due to a high melting point of stearyl group. In the case of the hydrated crystal (I) in this region, water was stably incorporated into its structure and, even after one month, no separation of water took place, whereby it is regarded that an $\alpha$-gel structure (26) is formed. When the attention is paid to the region of about $60^{\circ} \mathrm{C}$ and higher, a reversed hexagonal phase and a lamellar liquid crystalline phase appeared and, unlike the case of sodium oleate, a dispersed phase of lamellar liquid crystal $(\mathrm{LLC}+\mathrm{W})$ was present at the low concentration region.

From these facts, it is concluded that a molecular structure of ArgOA, in which oleic acid having a bulky structure as a hydrophobic moiety due to a cis-type double bond and arginine having a strong intermolecular interaction as a zwitterion are combined, is suitable for the formation of lamellar liquid crystals.

\subsection{Solution Properties in a Diluted Sys- tem of an ArgOA Aqueous Solution}

It is very important to know the solution properties of ArgOA in a diluted solution system for understanding the surface chemical characteristic of ArgOA. In view of the above, a surface tension versus concentration curve of ArgOA aqueous solution was prepared (Fig. 8). As will be apparent from Fig. 8, there were two

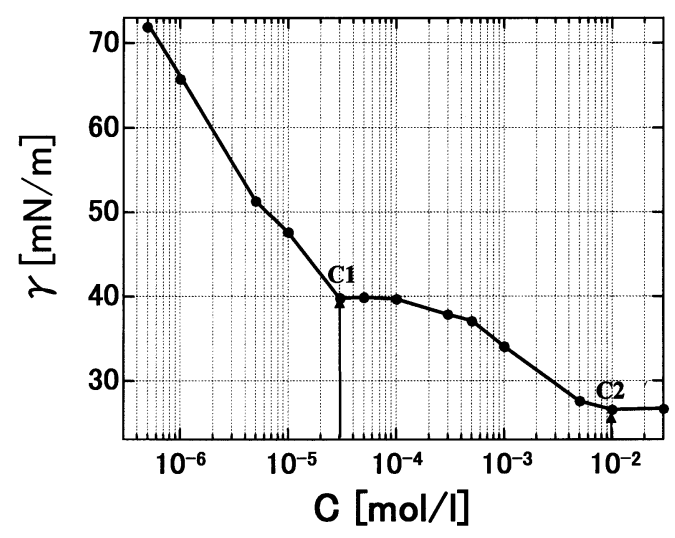

Fig. 8 Surface Tension v.s. Concentration of ArgOA at $25^{\circ} \mathrm{C}$.

bending points. Similar tendency was also reported for diluted aqueous solutions of a Pluronic type surfactant and of sodium salt of 1,2-dilauroylphosphatidylglycerol (DLPG) having an ability to form bilayer membrane and, at their bending points, it was analyzed that a phase change was resulted $(31,32)$. Therefore, the bending points of Fig. 8 were named the first $\mathrm{cmc}(\mathrm{C} 1$ : $\left.3.0 \times 10^{-4} \mathrm{M}\right)$ and the second cmc $\left(\mathrm{C} 2: 1.0 \times 10^{-2}\right.$ $\mathrm{M})$. When an attention is paid to the concentration range near these two points, a change was resulted in the appearance of the solution from $\mathrm{C} 1$ and, therefore, transmittance of the solution near $\mathrm{C} 1$ and $\mathrm{C} 2$ were measured (Fig. 9). The transmittance began to lower from $\mathrm{C} 1$ and lowered down to near $\mathrm{C} 2$. This is interpreted to be due to the co-existence of micelle and highly associated aggregates from near $\mathrm{C} 1$. Therefore, an aqueous solution between $\mathrm{C} 1$ and $\mathrm{C} 2$ was subjected to an obser-

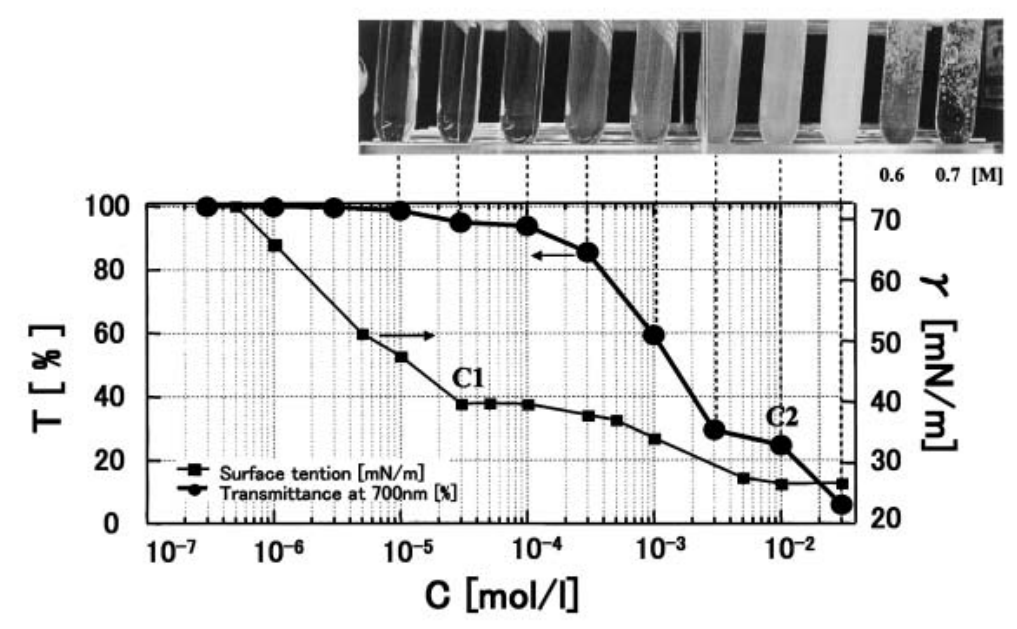

Fig. 9 Transmittance v.s. Concentration of $\mathrm{ArgOA}$ at $25^{\circ} \mathrm{C}$. 


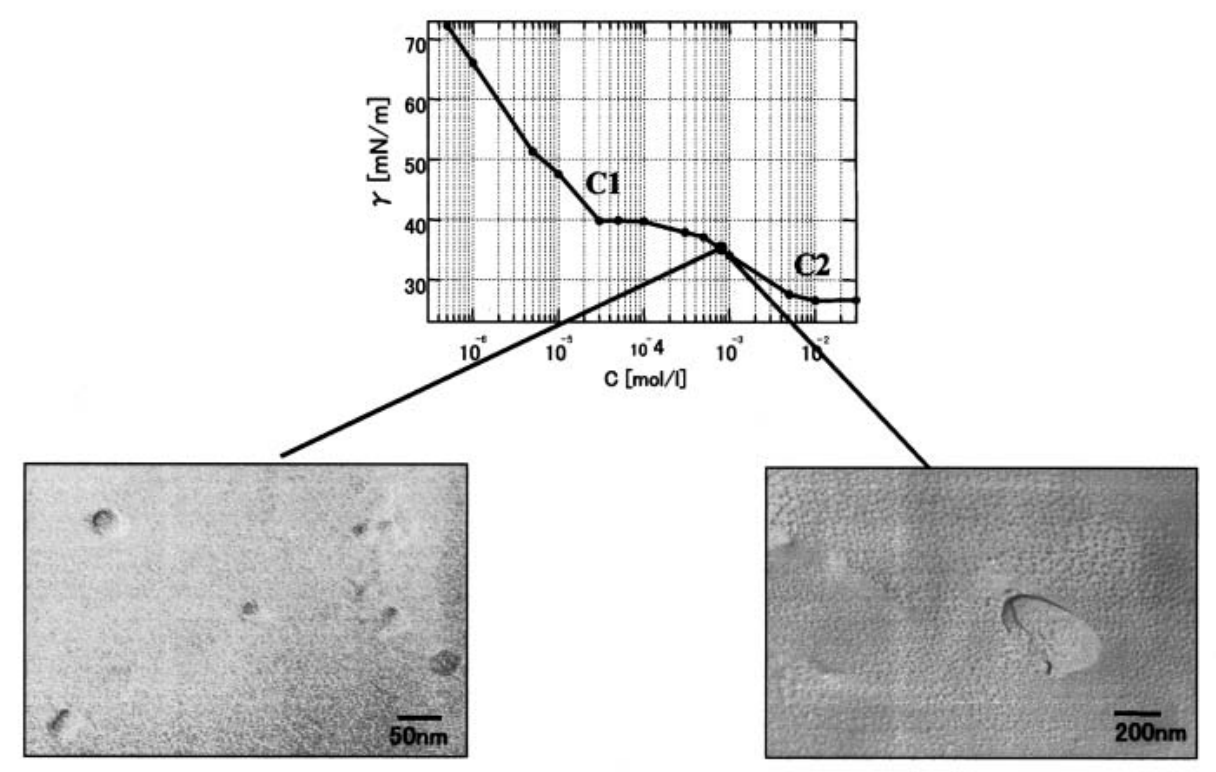

Fig. 10 Transmission Electron Microscopic Observation $\left(\operatorname{ArgOA} 1.0 \times 10^{-3} \mathrm{M}\right)$ in the region from $\mathrm{C} 1$ to $\mathrm{C} 2$.

vation under TEM by a freeze fracture method (Fig. 10). In this picture, granular substances (highly associated aggregates) of 10 to $50 \mathrm{~nm}$ and 200 to $300 \mathrm{~nm}$ were observed. Taking a decrease in transmittance of the solution from $\mathrm{C} 1$ to $\mathrm{C} 2$ and a high ability of $\mathrm{ArgOA}$ to form lamellar liquid crystals as mentioned already into consideration, there may be a high possibility that those highly associated aggregates are vesicles. From these results, it is considered that the area between $\mathrm{C} 1$ and $\mathrm{C} 2$ is a region where micelle-vesicle like highly associated aggregates coexist. After that, changes in the viscosity of ArgOA aqueous solution were resulted from near C2 (Fig. 11). Viscosity at the concentration

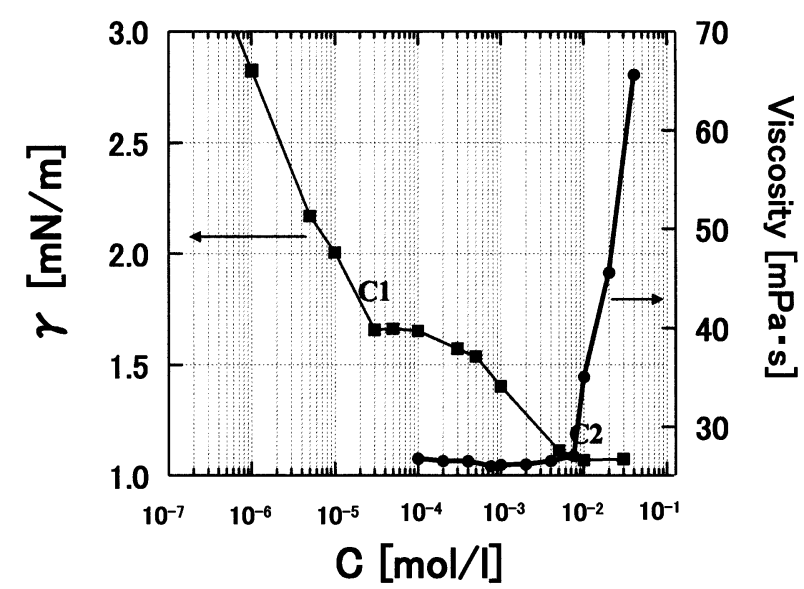

Fig. 11 Viscosity v.s. Concentration of ArgOA. range before $\mathrm{C} 2$ was similar to that of water but, after $\mathrm{C} 2$, it abruptly increased. The increase in the viscosity is judged to be due to a phase transition to a lamellar liquid crystalline phase region.

From these results, it has been cleared that ArgOA is able to form a highly associated aggregates from its diluted solution region.

\section{$3 \cdot 4$ Effect of L-arginine on the Formation of Highly Associated Aggregates}

As mentioned above, it has been found that, although $\mathrm{ArgOA}$ is a single-chained amphiphilic substance, it shows a specific phase behavior and forms a highly

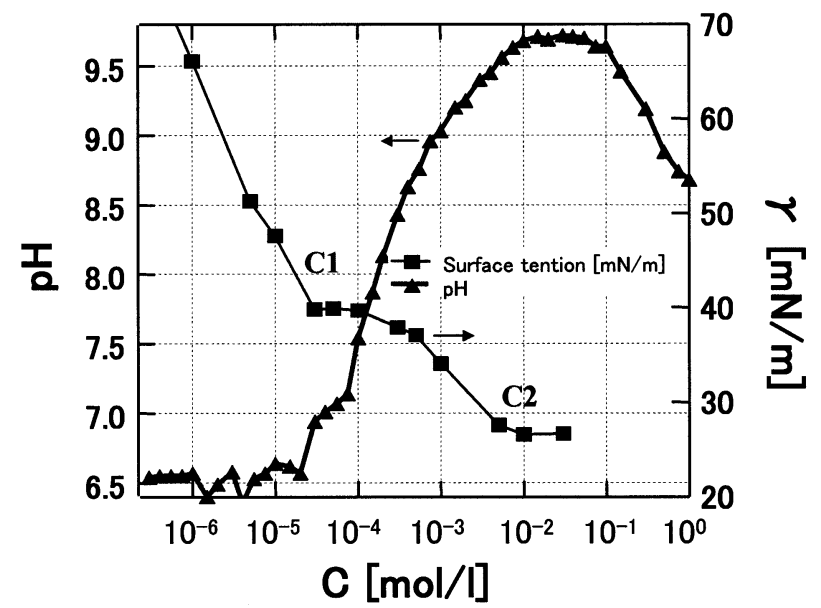

Fig. 12 pH v.s. Concentration of ArgOA. 
associated aggregates from very low concentrations. Such a specificity of the ArgOA should be greatly affected by a structural characteristic of oleic acid as a hydrophobic moiety as well as L-arginine as a counterion. Therefore, we focused on the counterion and investigated the effect of arginine on the formation of highly associated aggregates in a diluted solution system.

ArgOA is a fatty acid soap and the dissociation states of counterion is able to be presumed from the changes in $\mathrm{pH}$. Thus, the relation between $\mathrm{pH}$ and concentration of an ArgOA solution near $\mathrm{C} 1$ and $\mathrm{C} 2$ was investigated (Fig. 12). As will be apparent from Fig. 12, it was noted that the relation between $\mathrm{pH}$ and $\mathrm{ArgOA}$ concentration had a correlation to a surface tension versus concentration curve (transcribed from Fig. 8). Firstly, the $\mathrm{pH}$ began to increase from near $\mathrm{C} 1$ and, until $\mathrm{C} 2$, it increased almost in proportion to the concentration. The $\mathrm{pH}$ reached its maximum near $\mathrm{C} 2$ and, after that, a decrease in $\mathrm{pH}$ tended to become slow. If $\mathrm{C} 2$ is an initiation point for the phase transfer to the lamellar liquid crystalline phase, changes in $\mathrm{pH}$ should reflect the hydrated state around the bonded area of guanidyl group in strongly basic arginine for carboxyl group of oleic acid, whereby its relation with the associated state may be presumed as well. Accordingly, in order to investigate the state around the bonded area, chemical shift of amino group proton was measured by means of ${ }^{1} \mathrm{H}-\mathrm{NMR}$ (Fig. 13). As noted in this figure, when ArgOA concentration increased from C2 $(0.01 \mathrm{M})$ which is judged to be an initiation point for the phase

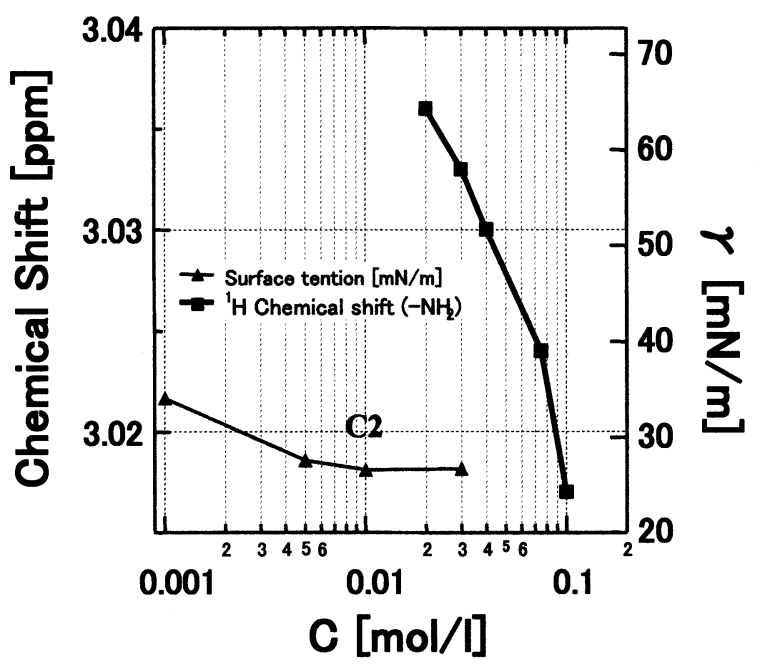

Fig. $13{ }^{1} \mathrm{H}-\mathrm{NMR}$ Chemical Shift in ppm in $\mathrm{D}_{2} \mathrm{O}$ (Chain- $\mathrm{NH}_{2}$ ). transfer as mentioned above to $0.1 \mathrm{M}$, chemical shift was shifted to the side of an up-magnetic field. Generally speaking, nucleus of atom having a relatively high electron density appears in an upfield while nucleus of atom having a relatively low electron density appears in a downfield. In accordance with such a qualitative chemical shift rule (33), it is meant that, as the ArgOA concentration increased, dissociation degree of amino group (a guanidyl group of arginine in the present case) lowered (lowering in deviation of electron density), whereby the electron density became high and amino group proton appeared in the area of an upfield. Therefore, it is able to be concluded that changes in $\mathrm{pH}$ reflect the hydrated state around the bonded area. From the above, with regard to the formation of lamellar liquid crystals of $\mathrm{ArgOA}$, it is considered that, as the concentration increases, an interaction in the two-dimensional direction (in a lateral direction) between adjacent L-arginine molecules becomes strong and the hydrating ability of the bonded area lowers. Therefore, a dissociation degree of the bonded area of L-arginine guanidyl group lowers (lowering in $\mathrm{pH}$ ), a hydrophobic interaction is further accelerated and a formation of the associated aggregates is promoted, as a result of it, lamellar liquid crystal which is an infinitively associated aggregates is formed.

\section{Conclusion}

In spite of the fact that ArgOA is a single-chained amphiphilic substance, it has been found to have a characteristic to form lamellar liquid crystals over a wide ranges of temperature and concentration. It has been concluded that a structural characteristic as a result of a cis-type double bond of oleic acid and a structural balance with L-arginine are inevitable in the formation of lamellar liquid crystals. It has been also confirmed that ArgOA is able to form a lamellar liquid crystalline structure having a large amount of water.

\section{Acknowledgment}

The authors wish to offer our cordial and sincere thanks to Dr. Shigeo Asai of Tokyo Institute of Technology (Department of Chemistry and Materials Science, Graduate School of Science and Engineering) for his providing us with the opportunity of the SAXS measurement and giving the valuable suggestions and also to 
Mr. Kazuhito Maeda, General Manager, NOF Corporation and staff members of Oleo Chemicals Research Laboratory for their cooperation with us for freeze-drying, etc. of the samples in carrying out the present study.

\section{References}

1. S. ABRAHAMSSON and I. RYDERSTEDT-NAHRUNGBAUER, The Crystal Structure of the Low-Melting Form of Oleic Acid, Acta Crystallogr., Vol. 15, 1261-1268 (1962).

2. Ed.G. WEISSMAN and R. CLAIBORNE, Cell Membranes: Biochemistry, Cell Biology \& Pathology, HP Publishing Co., Inc., New York (1975).

3. C. TANFORD, The hydrophobic effect, 2nd edn., John Wiley \& Sons, Inc., New York (1980).

4. S.J. SINGER and G.L. NICOLSON, The Fluid Mosaic Model of the Structure of Cell Membranes, Science, Vol. 175, 720-731 (1972).

5. M. KITO, Phospholipids of Escherichia coli Membrane, Protein, Nucleic Acid, Enzyme, Vol. 17, 500-508 (1972).

6. M. KITO, Regulation of the Synthesis of Phospholipid Molecular Species in Escherichia coli Membranes, Biochemistry, Vol. 49, 1301-1315 (1977).

7. S. OHNISHI, Dynamic Structure of Biomembrane, Tokyo University publishing Co., Inc., Tokyo (1981).

8. K. SATO and M. KOBAYASHI, Lipid Structure and Dynamics, Kyoritsu publishing Co., Inc., Tokyo (1992).

9. M. SUZUKI, T. OGAKI and K. SATO, Crystallization and Transformation Mechanisms of $\alpha$-, $\beta$ - and $\gamma$-polymorphs of Ultra-Pure Oleic Acid, J. Am. Oil Chem. Soc., Vol. 62, 16001604 (1985).

10. K. OGINO, M. ABE, Y. GOTO, M. GOTO, Y. TANAKA, T. FUNADA and J. HIRANO, Surface Chemical Properties of Unsaturated Fatty Acids, J. Jpn Oil Chem. Soc., Vol. 39, 398404 (1990).

11. K. SATO, Structures and Physical Properties of Crystalline Fatty Acids and Triacylglycerols, J. Jpn Oil Chem. Soc., Vol. 44, 702712 (1995).

12. M. SUZUKI, Fatty Acid Type of Lipid as the Material, Hyomen(Surface), Vol. 38, 24-39 (2000).

13. P. TANDON, G. FORSTER, R. NEUBERT and S. WARTEWIG, Phase Transitions in Oleic Acid as Studied by Xray Diffraction and FT-Raman Spectroscopy, J. Molecular Structure, Vol. 524, 201-215 (2000).

14. M. ABE, K. TAKASAKA, Y. YOSHIHARA, K. OGINO, K. SATO and M. SUZUKI, Properties of W/O-type Emulsions with Surfactants and Oils Derived from Oleic Acid, Shikizai, Vol. 68, 135-141 (1995).

15. K. TAKASAKA, Y. YOSHIHARA, Y. HIRANO, H. SAKAI, K. SAITO, M. SUZUKI and M. ABE, Properties of O/W-type Emulsions with Surfactants and Oils Derived from High Purity Oleic Acid, Material Technology, Vol. 13, 279-285 (1995).

16. S. YOMO, Y. ENDO, T. KATO, T. SEIMIYA, M. IWAHASHI,
Y. KIDERA and M. SUZUKI, Fundamental Properties of Aqueous Solutions of Nonionic Surfactants Prepared from Oleic Acid of High Purity, J. Jpn Oil Chem. Soc., Vol. 46, 873-878 (1997).

17. N. HASHIDA, M. MURAKAMI, H. YOSHIKAWA, K. TAKADA and S. MURANISHI, Intestinal Absorption of Carboxyfluorescein Entrapped in Liposomes in Comparison with Its Administration with Lipid-surfactant Mixed Micelles, J. Pharm. Dyn., Vol. 7, 195-203 (1984)

18. B.W. BARRY, Mode of Action of Penetration Enhancers in Human Skin, J. Controlled Release, Vol. 6, 85-97 (1987).

19. B. ONGPIPATTANTAKUL, R.R. BURNETTE, R.O. POTTS and M.L. FRANCOEUR, Evidence that Oleic Acid Exists in a Separate Phase within Stratum Corneum Lipids, Pharm. Res., Vol. 8, 350-354 (1991).

20. F. YAMASHITA, H. BANDO, Y. KOYAMA, S. KITAGAWA, Y. TAKAKURA and M. HASHIDA, In vivo and in vitro Analysis of Skin Penetration Enhancement Based on a Two-Layer Diffusion Model with Polar and Nonpolar Routes in the stratum Corneum, Pharm. Res., Vol. 11, 185-191 (1994).

21. D.M. SMALL, Lateral Chain Packing in Lipids and Membranes, J. Lipid Research, Vol. 25, 1490-1500 (1984).

22. M.R. RICH, Conformational Analysis of Arachidonic and Related Fatty Acids Using Molecular Dynamics Simulations, Biochim. Biophys. Acta, Vol. 1178, 87-96 (1993).

23. T. TAKEHARA, Functions and Applications of Amino Acids, Fragrance Lournal, No. 89, 69-76 (1988).

24. Chemical Handbook I, Maruzen Co., Inc., 609 (2003).

25. T. HIRANO, Recent Studies on Natural Moisturizing Factors, Fragrance Journal, No. 17, 14-19 (2000).

26. M. KODAMA and S. SEKI, Thermoanalytical Investigation on the Coagel-Gel-Liquid Crystal Transition in Some WaterAmphiphile Systems, Progress in Colloid and Polymer Sci., Vol. 68, 158-162 (1983).

27. T. KANEKO and H. SAGITANI, Formation of Homogeneous Liposomes with High Trapping Efficiency by the Surface Chemical Method, Colloids and Surfaces, Vol. 69, 125-133 (1992).

28. D.M. SMALL, Phase Equilibria and Structure of Dry and Hydrated Egg Lecithin, J. Lipid Research, Vol. 8, 551-557 (1967).

29. T. SUZUKI, H. TAKEI and S. YAMAZAKI, Formation of Fine Three-Phase Emulsions by the Liquid Crystal Emulsification Method with Arginine $\beta$-branched Monoalkyl Phosphate, J. Colloid \& Interface Sci., Vol. 129, 491-500 (1989).

30. H. KUNIEDA, The Mechanism of Dissolution of Quaternary Ammonium Chlorides Containing Two Long-Chain Alkyl Groups in Water, J. Chem. Soc. Jpn., No. 2, 151-156 (1977).

31. Y. SAITO, Y. KONDOH, M. ABE and T. SATOH, Effects of Temperature on Micellar Formation and Micellar Structure on Pluronic L-64, Yakugakuzasshi, Vol. 114, 325-332 (1994).

32. Nihonkagakukai, Koroido Kagaku III, Tokyokagakudoujin, pp. 145-149 (1996).

33. R.M. SILVERSTEIN, G.C. BASSLER and T.C. MORRIL, Spectrometric Identification of Organic Compounds, 4th edn, John Wiley \& Sons, Inc., New York (1981). 